\title{
Elektrikli Araçlarda Batarya-Ultrakapasitör Enerji Depolama Sistemi Bağlantı Topolojilerinin Değerlendirilmesi
}

\author{
1*Akif Demirçalı ve ${ }^{1}$ Selim Köroğlu \\ ${ }^{1}$, Elektrik Elektronik Mühendisliği Bölümü, Mühendislik Fakültesi Pamukkale Üniversitesi, Denizli, Türkiye
}

\section{Özet:}

Tamamen elektrikli araçlarda, Batarya ve Ultrakapasitör (UC) enerji depolama birimlerinin birlikte kullanılması sıklıkla tercih edilmektedir. Burada ana enerji kaynağı olarak batarya kullanılırken yardımcı kaynak olarak UC kullanılmaktadır. Böylelikle aracın temel güç ihtiyacı bataryalardan karşılanırken anlık güç talepleri UC tarafından sağlanır. İki kaynağın birlikte kullanılmasında pasif, yarı aktif ve aktif olmak üzere; birçok bağlantı grupları oluşturulabilmektedir. Bu çalışmada, en yaygın kullanılan beş farklı bağlantı topolojisi için ağırlık, maliyet, kontrol karmaşıklığı, bataryadan faydalanma oranı, UC'nin etkin kullanımı, sistem verimi gibi göreceli bir karşılaştırma yapılmıştır. Yapılan değerlendirmede yarı aktif UC topolojinin en avantajlı seçenek olduğu sonucuna varılmıştır.

Anahtar kelimeler: Elektrikli araç, enerji depolama birimleri, batarya, ultrakapasitör, hibrit topoloji

\begin{abstract}
:
In purely electric vehicles, it is often preferred to use Battery and Ultracapacitor (UC) energy storage units together. Here, the battery is used as the main energy source, while the UC is used as the auxiliary source. Thus, while the basic power requirement of the vehicle is met from the batteries, the instantaneous power demands are provided by the UC. In the use of two sources together, many connection groups can be formed such as passive, semi-active and active. In this study, a relative comparison is made for the five most commonly used connection topologies such as weight, cost, control complexity, battery utilization rate, effective use of UC, and system efficiency. In the evaluation, it is concluded that the semi-active UC topology is the most advantageous option.
\end{abstract}

Keywords: Electric vehicle, energy storage units, battery, ultracapacitor, hybrid topology

\section{Giriş}

Günümüz dünyasında ulaşım sektörü önemli ölçüde yenilenmeyen yakıtlara bağlıdır. Bu sektörün hacmi ve büyüklüğü göz önünde bulundurulduğunda, içten yanmalı motor kullanan geleneksel araçların neden olduğu hava kirliliği, gürültü gibi çevresel etkiler halen kaygı verici düzeydedir. Bunların yanında petrol kaynaklı yakıtların tükenmesi gibi ciddi sorunlarla yüz yüze olduğumuz bir gerçektir $[1,2]$. Dünya genelinde otomotiv sektörünün çevre ve enerji sürdürülebilirliği konusunda karşılaş̧ı̆̆ı sorunların çözümünde elektrikli araçlar önemli bir rol oynamaktadır [3-5].

Elektrikli araçları genel olarak üç grup altında toplamak mümkündür. Birincisi, içten yanmalı ve elektrik motorlarının birlikte kullanılmasıyla oluşturulan hibrit araçlardır. Bu hibrit araçlar,

*Corresponding author: Akif Demirçalı Address: Faculty of Engineering, Department of Electrical Electronics Engineering, Pamukkale University, 20140, Denizli TURKEY. E-mail address: akifdemircali@pau.edu.tr 
içerisinde batarya barındırmakta, bataryanın şarj edilmesi içten yanmalı motor tarafından tahrik edilen generatör sistemi tarafından sağlanmaktadır. İkinci olarak, yine içten yanmalı ve elektrik motorun birlikte kullanıldığı ancak elektrik motorunun tahriki sağlayan batarya harici olarak elektrik şebekesinden şarj edilebilmektedir. Bunlara fişli hibrit elektrikli araçlar denmektedir. Üçüncü grupta ise batarya sistemi tarafından beslenen tamamen elektrikli araçlar yer almaktadır. $\mathrm{Bu}$ araçlarda sadece batarya beslemesi kullanılmasının yanında birden fazla enerji depolama sisteminin bulunduğu hibrit konfigürasyonlar da mümkündür. $\mathrm{Bu}$ yap1, hibrit enerji depolama sistemi olarak tarif edilmektedir. Yani aracın enerjilendirilmesinde ana besleme kaynağı olarak bataryanın kullanılmasına ilave olarak ultra-kapasitör (UC), lityum iyon kapasitör, yakıt hücresi vb. yardımcı besleme kaynakları bulunmaktadır [6-8].

Elektrikli araçlar son zamanlarda büyük ilgi görmeye başlamış ve aynı paralelde batarya teknolojilerinde de önemli gelişmeler yaşanmaktadır [9-10]. Ancak, halen batarya teknolojileri mevcut elektrikli araçlardaki güç ihtiyacına bağlı enerji talebini tam olarak karşılamakta bazı yetersizliklere sahiptir. En önemli sorunlarının başında aşırı şarj, bataryanın elektrokimyasal yapılarındaki bozulma ve ani güç taleplerine karşı dinamik cevaplarının yavaş olması gösterilebilir. Elektrikli araçların enerji ihtiyacının karşılanmasında, enerji yoğunluğu, güç yoğunluğu, kullanım ömrü, maliyet ve bakım gibi kriterler önemli parametrelerdir. Bataryalar genellikle yüksek enerji yoğunluklarına sahiptir ve yerleşik elektrik enerjisinin çoğunu depolayabilirler. Bir başka alternatif enerji depolama kaynağı yakıt hücreleridir. Ancak bu kaynaklarda uzun zaman sabitleri araçlar üzerindeki performansını sınırlar. Öte yandan, UC'ler yüksek güç yoğunluğu, yüksek verimlilik, uzun ömür ve hızlı yanıt veren şarj / deşarj karakteristiklerine sahiptir [11-13]. Ancak bunların hiçbiri tek başına elektrikli araçların tüm gereksinimlerini karşılayamaz.

Batarya ve UC'lerin kombinasyonu, elektrikli araçların enerji depolama sistemi için yüksek güç yoğunluğu ve yüksek enerji yoğunluğu gereksinimlerini karşılamak için etkili bir çözüm sunmaktadır [14]. Bu anlamda, hibrit enerji depolama sistemi olarak batarya ve UC'lerin birlikte kullanımı tercih edilen en yaygın konfigürasyondur. Bu kombinasyon, doğası gereği, ikisinin tek başına kullanımına kıyasla daha iyi performans sunar. Böylelikle yardımcı depolama birimi olarak kullanılan UC'ler yüksek güç yoğunluklarıyla bataryaların bu konudaki eksiğini kapatmaktadır [15]. Ayrıca, uzun kullanım ömürleri sayesinde batarya üzerindeki stresin azaltılması ve kullanım ömrünün arttırılmasına katkı sağlarlar [16-17]. Hibridizasyon yalnızca enerji depolama sisteminin verimliliğini artırmakla kalmaz, aynı zamanda güç aktarma sistemi verimliliğini ve pil ömrünü de artırır.

Literatürde yapılan çalışmalarda birçok topoloji önerilmiştir [18-23]. Bu çalışmada, batarya/UC enerji depolama sistemlerinin birlikte kullanılmasında en yaygın kullanılan beş farklı topoloji incelenmiş ve birbiriyle karşılaştırılması yapılmıştır. Farklı bağlantı topolojilerinin değerlendirmesi yapılarak, topoloji seçimini etkileyen parametreler tartışılmış ve uygun bağlantı modelinin seçimi için öneriler getirilmiştir.

\section{Elektrikli Araç Topolojileri}

Tamamen elektrikli araçlarda gerekli olan güç ihtiyacı, bilindiği gibi bataryalar tarafından karşılanır. Ancak birçok uygulamada ana güç kaynağı batarya yanında UC gibi yardımcı güç kaynakları da kullanılmaktadır. Birden çok depolama birimi bulunan elektrikli araçlarda depolama 
birimlerinin yerleşimi ve birbirleriyle olan bağlantıları oldukça önemlidir. Bu anlamda literatürde pasif, yarı aktif ve aktif olmak üzere birçok bağlantı topolojisi önerilmiş̧ir [24]. Şekil 1'de BataryaUC enerji depolama sistemi hibritizasyon topolojilerinin genel sınıflandırması yapılmıştır. Seçilecek topoloji; aracın çalışma karakteristiği, araç bileşenlerinin verimi, depolama birimlerinin kullanım ömrü vb. durumlar üzerinde etkili olmaktadır. Dolayısıyla, bu durum sistemin genel performansını etkilediği için göz ardı edilmemelidir. Bu sebeple, enerji depolama birimlerinin yerleşim topolojileri iyi incelenmeli ve ihtiyaca göre doğru topoloji seçilmelidir.

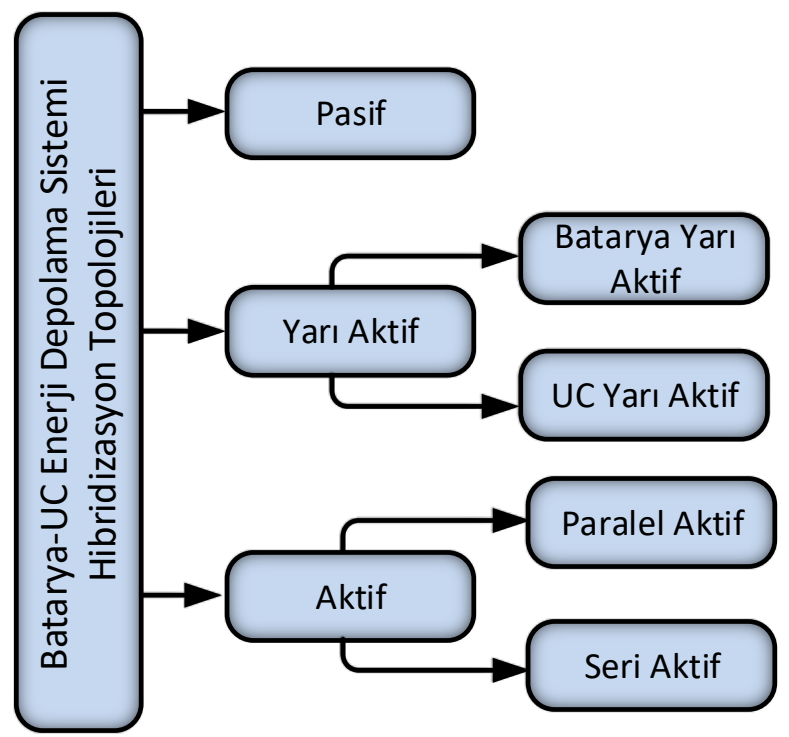

Şekil 1. Batarya-UC enerji depolama sistemi hibridizasyon topolojilerinin sınıflandırması [24]

\subsection{Pasif bağlantı modeli}

Pasif bağlantı topolojisi, batarya ve UC'nin herhangi bir dönüştürücü kullanmadan doğrudan DC baraya bağlanmasıyla oluşmaktadır [25-28]. Bağlantı yapısı Şekil 2'de gösterilmiş olan bu model basit ve ek bir dönüştürücü elemanı gerektirmediğinden sıklıkla tercih edilmektedir. Ancak, batarya ve UC'den istenildiği ölçüde yararlanılmasına imkan tanımamaktadır. UC'nin geriliminin batarya gerilimi ile sürekli aynı olması sebebiyle, UC'den alınabilecek ya da depolanabilecek enerji sınırlı olmaktadır. Bu topolojide herhangi bir kontrol algoritması yoktur. Her bir güç kaynağının şarj ve deşarj kontrolleri aslında kendi iç direnç değerlerine (şarj ve deşarj dirençleri) göre gerçekleş̧irilir. Dolayısıyla, batarya ve UC arası güç paylaşımının yönetilmesi gibi bir durum söz konusu değildir. Burada yardımcı besleme kaynağı olarak kullanılan UC, hızlı şarj/deşarj karakteristiğinden dolayı, yalnızca anlık akım ihtiyacı durumunda destek vermektedir. Pasif topoloji yapı olarak basit ve uygun maliyetli olmasına rağmen, arzu edilen sistem performansı sağlamamaktadır. 


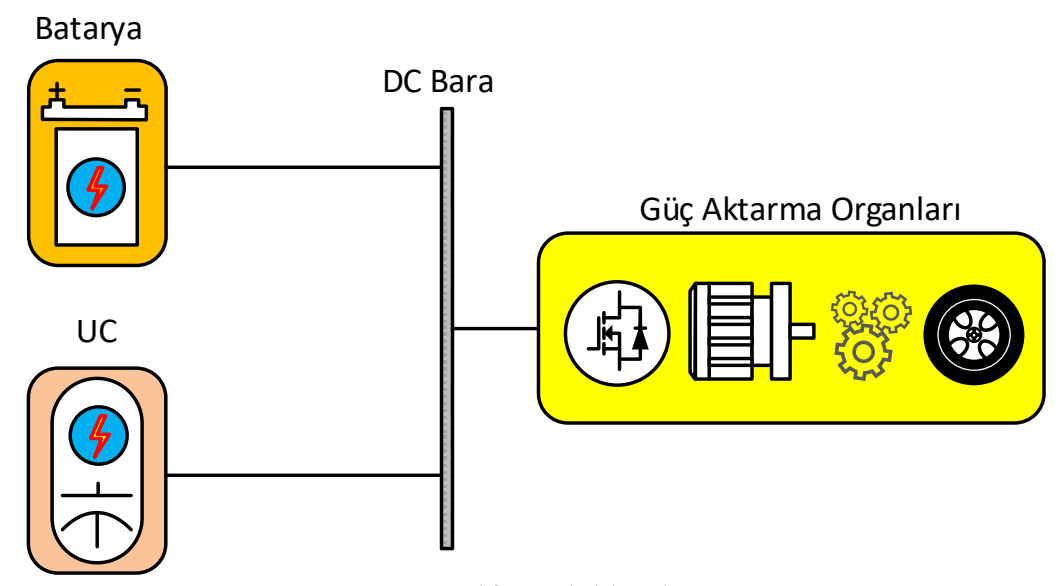

Şekil 2. Pasif paralel bağlantı.

\subsection{Yarı aktif bağlantı modeli}

Batarya veya UC'nin bir DC-DC dönüştürücü üzerinden DC baraya paralel bağlanmasıyla oluşturulan düzene yarı aktif bağlantı modeli denilmektedir. Bu bağlantı biçimi iki farklı şekilde düzenlenebilmektedir [28]. Bunlardan ilki batarya DC-DC dönüştürücü üzerinden, UC ise doğrudan DC baraya bağlı olup ilişkili topoloji Şekil 3'de gösterilmiş̧ir. Buna batarya yarı aktif topolojisi ismi verilir. Bara gerilimi UC'nin gerilimine bağlı olduğundan motor sürücülerinin verimi, sabit bara gerilimi olan duruma göre düşmektedir [23]. Bu düzenlemede, yük talebindeki dalgalanmalardan bağımsız olarak batarya akımının kontrolünde iyileştirme sağlanır. Ayrıca, batarya geriliminin DC barayla aynı olması gerekmediğinden batarya paketinin farklı şekillerde boyutlandırılabilir. Bununla birlikte, UC'nin doğrusal şarj/deşarj özellikleri, DC bağlantı geriliminde keskin dalgalanmalara neden olarak sistem performansının düşmesine neden olur. $\mathrm{Bu}$ nedenle, DC bara gerilimini stabilize etmek için, daha yüksek kapasiteli UC'ye ihtiyaç duyulur ve dolayısıyla sistemin maliyeti bu oranda $\operatorname{artar}[24,29]$. Sonuç olarak pasif paralel bağlantıya göre avantaj sağlamasına rağmen UC'den arzu edilen ölçüde yararlanma olanağı vermez, toplam sistem veriminde istenilen artış sağlanmaz.

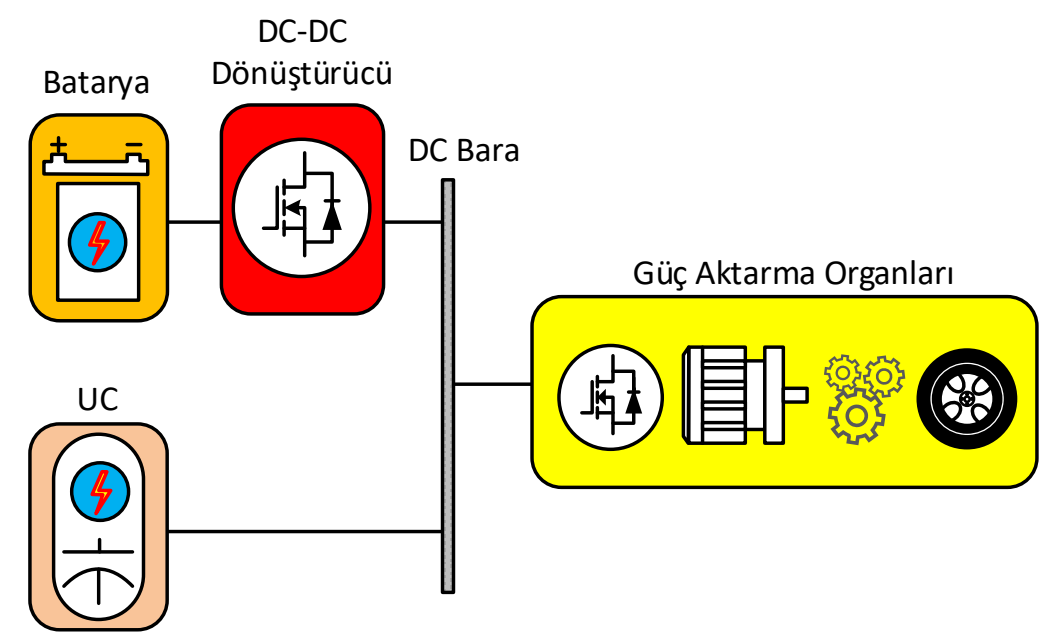

Şekil 3. Batarya yarı aktif bağlantı topolojisi 
Yarı aktif bağlantı topolojilerinden bir diğeri UC yarı aktif topoloji olarak adlandırılır. Burada batarya DC baraya doğrudan, UC ise bir DC-DC dönüştürücü üzerinden bağlanmaktadır. Bağlantı topolojisi Şekil 4'te gösterilmiştir. Bara gerilimi batarya gerilimine bağlıdır ve neredeyse sabit kalmaktadır [22]. Buna karşın UC gerilim depolamalı bir aygıt olduğundan şarj durumuna bağlı olarak terminal gerilimi doğru orantılı değişir. Doğrudan paralelleme gibi topolojiler UC'nin şarj aktarım yeteneklerini sınırlayarak sabit batarya potansiyeliyle kenetlenmesiyle sonuçlanır [30]. Yüksek performanslı güç paylaşımı için UC yarı aktif bağlantı topolojisi tercih edilir. UC gerilimi DC-DC dönüştürücü tarafından arzu edildiği ölçüde ayarlanabileceği için UC'den yüksek düzeyde faydalanılabilir. Böylelikle, araç tarafından talep edilen anlık güçler UC tarafından karşılanabilir. Aynı zamanda generatör modunda üretilen fazla enerji yine dönüştürücü üzerinden UC'de depolanabilir. Böylelikle, doğru bir enerji yönetim stratejisi ile yukarıda belirtilen diğer topolojilere göre daha iyi bir performans elde edilebilir.

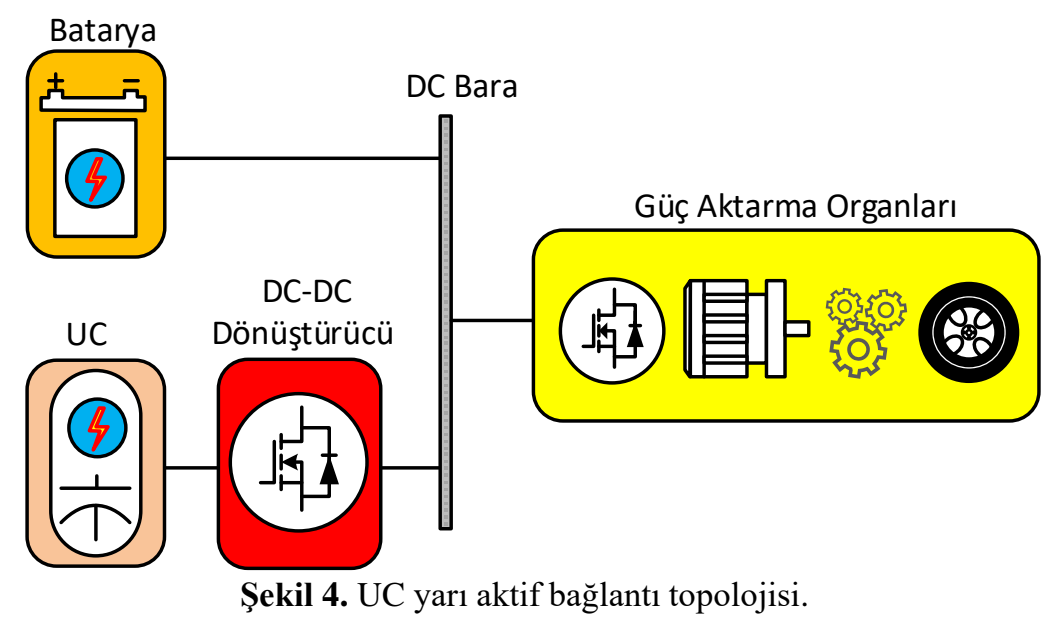

\subsection{Tam aktif bağlantı modeli}

Hem batarya hem de UC'nin, DC baraya bir DC-DC dönüştürücü vasitasıyla bağlanması durumunda oluşturulan modele tam aktif bağlantı topolojisi denir. Literatürde tam aktif bağlantı modeli için birçok topoloji önerilmiştir [31-37]. Bunlardan en yaygın kullanılanları tam paralel aktif ve tam seri aktif olarak iki sınıfta gösterilebilir. İlki olan tam paralel aktif topolojinin bağlantı modeli de Şekil 5 'te gösterilmiştir. Bu topolojide hem batarya hem de UC, DC-DC dönüştürücüler vasitasıyla DC baraya paralel bir şekilde bağlanmaktadır. Hem bataryanın hem de UC'nin gerilimleri DC bara geriliminden daha düşük tutulabilir. Böylelikle, her iki enerji depolama biriminden de en yüksek düzeyde yararlanılarak yerleştirilecek olan depolama birimlerinin boyutları bir miktar küçültülebilir. UC'nin voltajı geniş bir aralıkta değişebileceği için daha etkin bir kullanım olanağı elde edilir. Ancak, bu yöntemde iki tam boyutlu dönüştürücüye ihtiyaç duyulması araca ilave ağırlık ve maliyet getirecektir. Aynı zamanda, iki dönüştürücünün kontrolü ve koordinasyonu sistemin karmaşıklığını arttırmaktadır. 


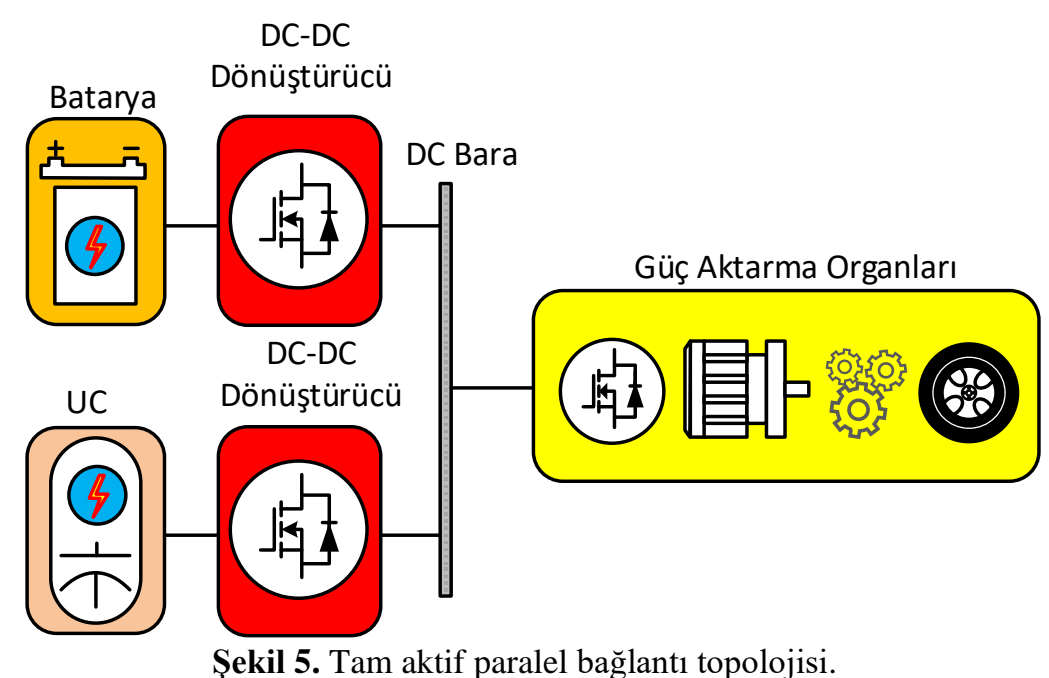

İkinci tam aktif topoloji ise seri bağlantılı topoloji olup Şekil 6'da gösterilmiştir. Burada, batarya bir DC-DC dönüştürücü üzerinden UC'ye, UC'de yine bir DC-DC dönüştürücüyle seri bir şekilde DC baraya bağlanmaktadır. Böylelikle değişken bara geriliminin getirdiği olumsuzluk önemli ölçüde ortadan kaldırılmıştır [38-39]. Yine burada da iki DC-DC dönüştürücünün getirdiği ağırlık ve karmaşıklık dezavantajı bulunmaktadır.

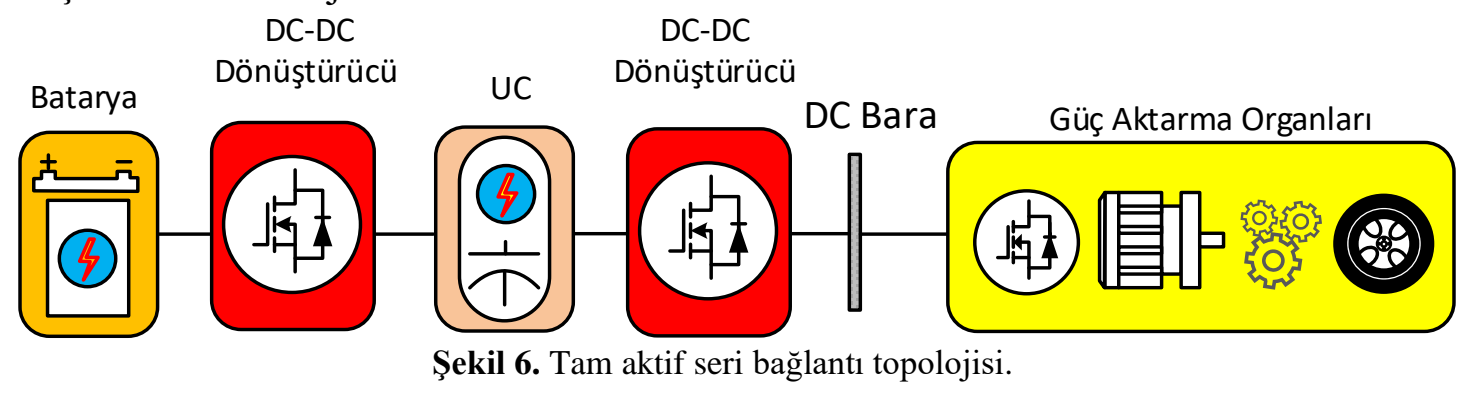

\section{Topolojilerinin Değerlendirilmesi ve Öneriler}

Tamamen elektrikli araçlarda ana enerji kaynağı olarak bataryanın, yardımcı besleme kaynağı olarak UC'nin birlikte kullanılması sıklıkla tercih edilir. Buradaki kaynaklarının bağlantı hibritizayonu sistem performansı üzerinde önemli etkilere sahiptir.

Bu çalışmada, en yaygın kullanılan topolojiler; ağırlık, maliyet, kontrol karmaşıklığı, bataryadan faydalanma, UC'den faydalanma ve motor sürücüsü verimine etkisi dikkate alınarak bir değerlendirme yapılmıştır. Bu değerlendirme kriterlerine göre batarya/UC hibritizasyonu bağlantı topolojilerinin karşılaştırması Şekil 7'de gösterilmiştir. İlk topoloji pasif bağlantı olup batarya ve UC DC baraya paralel bağlıdır. En basit ve ucuz düzenleme olmasına rağmen kontrolsüz yapısı gereği güç yönetimi açısından birçok olumsuzluk içerir. İkinci topolojide, batarya DC baraya DC/DC dönüştürücü üzerinden, $\mathrm{UC}$ ise direkt olarak bağlanır. Ana enerji kaynağı olarak bataryanın çalışma verimliliğini $\mathrm{DC} / \mathrm{DC}$ dönüştürücü üzerinden ayarlayabilir, böylece sistemin toplam verimliliği iyileştirilir. Ancak UC direkt DC baraya bağlı olduğundan etkin bir gerilim aralığında çalıştırılamamaktadır. UC'nin şarj/deşarj miktarı bara gerilimine bağlı olduğundan etkin kullanımı 
sınırlıdır. Yine yarı aktif olan üçüncü topolojide, UC DC/DC dönüştürücü üzerinden, batarya ise diretk seri olarak DC baraya bağlanır. UC'nin gerilim aralığı şarj/deşarj durumuna bağlı olarak DC/DC dönüştürücü üzerinden kontrol edilir. Böylelikle, enerji düzeyinden etkin bir yaralanma olanağı kazanılır. Dört ve beşinci topoloji tam aktif düzenleme olup her bir kaynak için ayrı ayrı DC/DC dönüştürücü kullanılmaktadır. Böylelikle her iki enerji kaynağının çıkış gücü hassas bir şekilde kontrol edilebilir. Ancak sistemdeki artan DC / DC dönüştürücüler enerji verimliliğini düşürecek, hem de sisteme ilave ağırlık ve maliyet getirecektir. Ayrıca sistemin kontrolü daha karmaşık olacaktır.

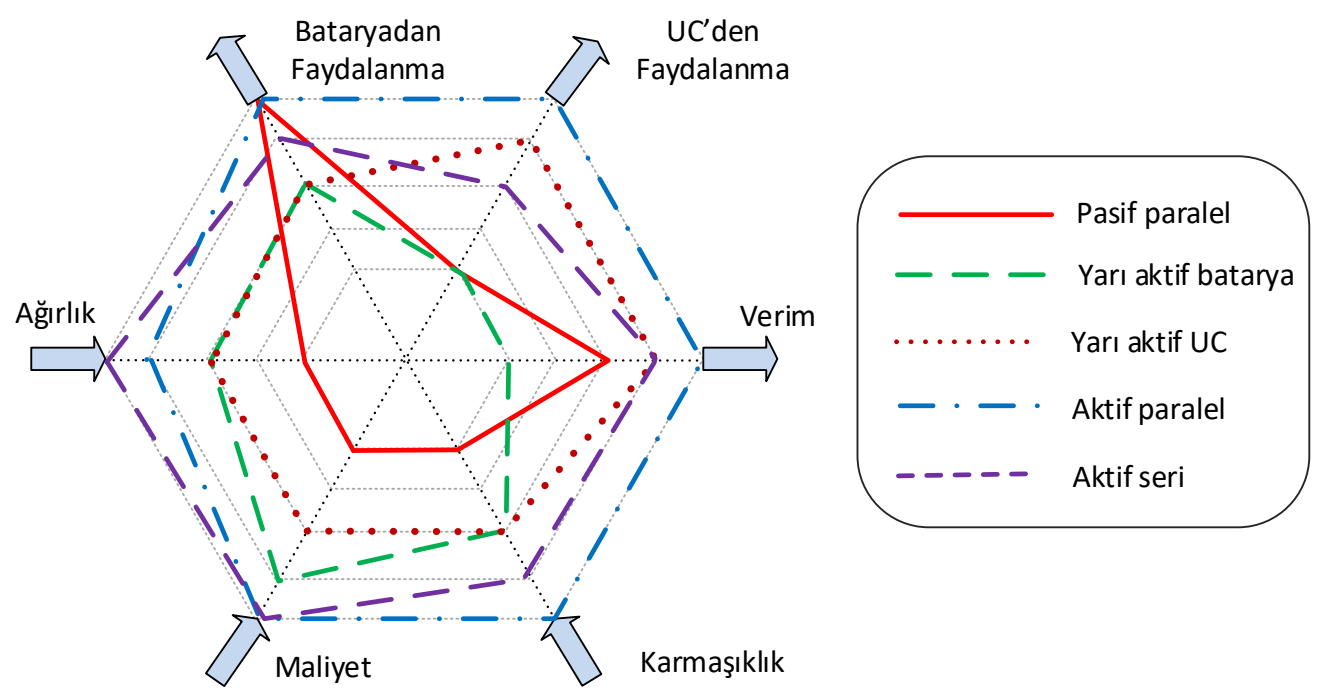

Şekil 7. Batarya - UC bağlantı topolojilerinin karşılaş̧ırılması.

Değerlendirme kapsamına alınan bu beş farklı topoloji üstünlük ve olumsuzlukları karşılaştırmalı olarak Tablo 1'de verilmişstir.

Tablo 1. Elektrikli araç topolojilerinin karşılaştırması

\begin{tabular}{|c|c|c|c|}
\hline $\begin{array}{l}\text { Batarya UC bağlantı } \\
\text { topolojileri }\end{array}$ & Üstün yanları & Olumsuz yanları & Değerlendirme skoru \\
\hline Pasif paralel & $\begin{array}{l}\text { Basit yap1, düşük } \\
\text { maliyet ve ağırlık }\end{array}$ & $\begin{array}{l}\text { Kontrol edilemez, } \\
\text { yönetilebilir değil }\end{array}$ & $* *$ \\
\hline Batarya yarı aktif & $\begin{array}{l}\text { Kontrol edilebilir } \\
\text { batarya gücü, }\end{array}$ & $\begin{array}{l}\text { İlave güç elektroniği } \\
\text { donanımı gerektir, } \\
\text { UC'den etkin yararlanma } \\
\text { imkanı zayıf }\end{array}$ & *** \\
\hline UC yarı aktif & $\begin{array}{l}\text { Kontrol edilebilir UC } \\
\text { gücü, aktif güç } \\
\text { paylaşımı, UC'den etkin } \\
\text { yararlanma }\end{array}$ & $\begin{array}{l}\text { İlave güç elektroniği } \\
\text { donanımı gerektir }\end{array}$ & $* * * * *$ \\
\hline Aktif paralel & $\begin{array}{l}\text { Etkin kontrol edilebilir } \\
\text { güç paylaşımı }\end{array}$ & $\begin{array}{l}\text { Karmaşık kontrol, daha } \\
\text { fazla donanım, yüksek } \\
\text { maliyet }\end{array}$ & $* * * *$ \\
\hline Aktif seri & $\begin{array}{l}\text { Kontrol edilebilir güç } \\
\text { paylaşımı }\end{array}$ & $\begin{array}{l}\text { Karmaşık kontrol, daha } \\
\text { fazla donanım, yüksek } \\
\text { maliyet }\end{array}$ & $* * *$ \\
\hline
\end{tabular}


Yarı aktif konfigürasyon; kontrol karmaşıklığının nispeten az olması, DC-DC dönüştürücü sayısını tek olması ve her bir depolama elemanını kontrol edilebilme olasılığı dikkate alındığında iyi bir ara çözüm vermektedir. Her ne kadar DC-DC dönüştürücü eklenmesi ile ağırlık artışı meydana geleceği düşünülse de bazı durumlarda diğer birimler daha verimli kullanıldığı için batarya veya UC boyutunun küçültülmesiyle bu dezavantaj da ortadan kalkmaktadır [40]. Topolojilerin sağladığ 1 üstünler ve olumsuzluklar dikkate alınarak yapılan değerlendirme indeksinde en iyi puanı UC yarı aktif topoloji almaktadır. Bu bağlantı modeli özellikle UC'den etkin yararlanma avantajı da dikkate alındığında en uygun çözüm olarak değerlendirilir.

\section{Sonuç}

$\mathrm{Bu}$ çalışmada elektrikli araçlarda enerjilendirme kaynağı olarak batarya ve UC'nin birlikte kullanılması durumunda beş farklı bağlantı topolojine ait değerlendirmeler yapılmıştır. Değerlendirme kriterleri olarak ağırlık, maliyet ve kontrol karmaşıklığı yanında bataryadan faydalanma oranı, UC'nin etkin kullanımı, sistem verimi dikkate alınmış. Bu kriterlere göre yapılan değerlendirmede en uygun bağlantı modeli olarak UC yarı aktif topolojinin seçilmesi önerilmiştir. $\mathrm{Bu}$ topolojide tek dönüştürücünün olması sistemin maliyet, ağırlık ve kontrol karmaşıklığını azaltmaktadır. Neredeyse sabit bir bara gerilimi sunmakta olup aynı zamanda etkin bir UC kullanım olanağı sağlamaktadır. Böylelikle araç tarafından talep edilen anlık güçler hızlı şarj/deşarj karakteristiği nedeniyle UC tarafından karşılanabilir. Aynı zamanda regeneratif modda üretilen fazla enerji yine dönüştürücü üzerinden UC'de depolanır. Buna bağlı olarak sistemin genel verimi, bataryanın kullanım süresi, ömrü ve menzil artırılır.

\section{Teşekkür}

Bu çalışması Pamukkale Üniversitesi Bilimsel Araştırma Projeleri Birimi tarafından 2020KRM008 nolu proje ile desteklenmiştir.

\section{Kaynakça}

[1] Chu S, Majumdar A. Opportunities and challenges for a sustainable energy future. Nature 2012;488(7411):294-303.

[2] Ferrero E, Alessandrini S, Balanzino A. Impact of the electric vehicles on the air pollution from a highway. Appl Energy 2016;169:450-9.

[3] Andwari AM, Pesiridis A, Rajoo S, Ricardo MB, Esfahanian V. A review of Battery Electric Vehicle technology and readiness levels. Renew. Sustain. Energy Reviews 2017;78:414-430.

[4] Hannan M, Hoque M, Mohamed A, Ayob A. Review of energy storage systems for electric vehicle applications: issues and challenges. Renew. Sustain. Energy Reviews 2017;69:771789.

[5] Xiong R, Cao J, Yu Q. Reinforcement learning-based real-time power management for hybrid energy storage system in the plug-in hybrid electric vehicle. Applied Energy 2018;211:538-548.

[6] Khaligh A, Li Z. Battery, Ultracapacitor, Fuel Cell, and Hybrid Energy Storage Systems for Electric, Hybrid Electric, Fuel Cell, and Plug-In Hybrid Electric Vehicles: State of the Art. IEEE Transactions on Vehicular Technology 2010;59(6):2806-2814. 
[7] Cao J, Emadi A. A New Battery/UltraCapacitor Hybrid Energy Storage System for Electric, Hybrid, and Plug-In Hybrid Electric Vehicles. IEEE Transactions on Power Electronics 2012;27(1):122-132.

[8] Emadi A, Rajashekara K, Williamson SS, Lukic SM. Topological overview of hybrid electric and fuel cell vehicular power system architectures and configurations. IEEE Trans. Veh. Technol. 2005;54(3):763-770.

[9] Lukic SM, Cao J, Bansal RC, Rodriguez F, Emadi A. Energy storage systems for automotive applications. IEEE Trans. Ind. Electron. 2008;55(6):2258-2267.

[10] Soltani M, Ronsmans J, Kakihara S, Jaguemont J, Van den Bossche P, Van Mierlo J, Omar N. Hybrid Battery/ Energy Storage System for a Pure Electric Bus for an Urban Transportation Application. Applied Sciences 2018;8(7):1176.

[11] Manzetti S, Mariasiu F. Electric vehicle battery technologies: from present state to future systems. Renew. Sustain. Energy Reviews 2015;51:1004-1012.

[12] Demircalı A, Sergeant P, Koroglu S, Kesler S, Öztürk E, Tumbek M. Influence of the temperature on energy management in battery-ultracapacitor electric vehicles. Journal of Cleaner Production 2018;176:716-725.

[13] Zhang S, Xiong R, Zhou X. Comparison of the topologies for a hybrid energy-storage system of electric vehicles via a novel optimization method. Sci. China Technol. Sci. 2015;58:11731185 .

[14] Koroglu S, Demircali A, Kesler S, Sergeant P, Ozturk E, Tumbek M. Energy management system optimization for battery- ultracapacitor powered electric vehicle. Journal of Electrical Systems 2017;13(1):16-26.

[15] Alobeidli K, Khadkikar V. A new ultracapacitor state of charge control concept to enhance battery lifespan of dual storage electric vehicles. IEEE Transactions on Vehicular Technology 2018;67(11):10470-10481.

[16] Rosario L. Power and energy management of multiple energy storage systems in electric vehicles. Cranfield University, PhD Thesis, 2007.

[17] Wang B, Xu J, Wai RJ, Cao B. Adaptive Sliding-Mode with Hysteresis Control Strategy for Simple Multimode Hybrid Energy Storage System in Electric Vehicles. IEEE Transactions on Industrial Electronics 2017;64(2):1404-1414.

[18] Kouchachvili L, Yaici W, Entchev E. Hybrid battery/supercapacitor energy storage system for the electric vehicles. Journal of Power Sources 2018;374:237-248.

[19] Arefin MA, Mallik A. Hybridization of battery and ultracapacitor for low weight electric vehicle. Journal of Mechanical and Energy Engineering 2018;2(42):43-50.

[20] Miller JM, Bohn T, Dougherty TJ, Deshpande U. Why Hybridization of Energy Storage is Essential for Future Hybrid, Plug-in and Battery Electric Vehicles. IEEE Energy Conversion Congress and Exposition, San Jose, CA, USA, 2009;2614-2620

[21] Geetha A, Subramani C. A comprehensive review on energy management strategies of hybrid energy storage system for electric vehicles. International Journal of Energy Research 2017;41:1817-1834.

[22] Kuperman A, Aharon I. Battery-ultracapacitor hybrids for pulsed current loads: A review. Renew. Sustain. Energy Reviews 2011;15(2):981-992.

[23] Tie SF, Tan CW. A review of energy sources and energy management system in electric vehicles. Renew. Sustain. Energy Reviews 2013;20:82-102. 
[24] Bhattacharyya P, Banerjee A, Sen S, Giri SK, Sadhukhan S. A modified semi-active topology for battery-ultracapacitor hybrid energy storage system for EV applications. IEEE Int. Conf. on Power Electronics, Smart Grid and Renewable Energy, Cochin, India, 2020;1-6.

[25] Bentley P, Stone DA, Schofield N. The parallel combination of a VRLA cell and supercapacitor for use as a hybrid vehicle peak power buffer. J. Power Sources 2005; 147:288-294.

[26] Choi ME, Kim SW, Seo SW. Energy management optimization in a battery/supercapacitor hybrid energy storage system. IEEE Transactions on Smart Grid 2012;3:463-472.

[27] Lam L, Louey R. Development of ultra-battery for hybrid-electric vehicle applications. J. Power Sources 2006;158:1140-1148.

[28] Choi S, Kim J, Yoon Y. Fabrication and characterization of a LiCoO2 battery-supercapacitor combination for a high-pulse power system. Journal of Power Sources 2004;138:360-3.

[29] Kuperman A, Aharon I, Malki S, Kara A. Design of a Semiactive Battery-Ultracapacitor Hybrid Energy Source. IEEE Transactions on Power Electronics 2013;28(2):806-815.

[30] Zhang Q, Li G. Experimental study on a semi-active battery-supercapacitor hybrid energy storage system for electric vehicle application. IEEE Transactions on Power Electronics 2020;35(1):1014-1021.

[31] Niemoeller B, Krein P. Battery-ultracapacitor active parallel interface with indirect control of battery current. IEEE power and energy conference 2010;12-9.

[32] Onar O, Khaligh A. Dynamic modeling and control of a cascaded active battery/ultracapacitor based vehicular power system. IEEE Vehicle Power Propulsion Conf. 2008;1-4.

[33] Amjadi Z, Williamson S. Power electronics based solutions for plug in hybrid electric vehicle energy storage and management systems. IEEE Trans. Ind. Electron. 2010;57(2):608-616.

[34] Tran DD, Barrero R, Hegazy O, Omar N, Van Mierlo J. An evaluation study of hybrid energy storage system for plug-in hybrid electric buses. IEEE Veh. Power Propuls. Conf. 2017;1-7.

[35] Lu S, Corzine K, Ferdowsi M. A newbattery / ultracapacitor energy storage system design and its motor drive integration for hybrid electric vehicles. IEEE Trans. Veh. Technol. 2007;56(4):1516-1523.

[36] Tran DD, Vafaeipour M, Baghdadi M, Barrero R, Van Mierlo J, Hegazy O. Thorough stateof-the-art analysis of electric and hybrid vehicle powertrains: Topologies and integrated energy management strategies. Renew. Sustain. Energy Reviews 2020;119:109596.

[37] Lukic SM, Wirasingha SG, Rodriguez F, Ca J, Emadi A. Power management of an ultracapacitor/battery hybrid energy storage system in an HEV. IEEE Vehicle Power and Propulsion Conf. 2006;1-6.

[38] Zimmermann T; Keil P, Hofmann M, Horsche MF, Pichlmaier S, Jossen A. Review of system topologies for hybrid electrical energy storage systems. J. Energy Storage 2016;8:78-90.

[39] Xiong R, Chen H, Wang C, Sun F. Towards a smarter hybrid energy storage system based on battery and ultracapacitor - A critical review on topology and energy management. Journal of Cleaner Production 2018;202:1228-1240. 